Fecha de entrega: 10 de marzo de 2011

Fecha de aprobación: 5 de abril de 2011

\title{
UNA AMISTAD FILOSÓFICA* CIORAN Y SU AMIGO ITALIANO MARIO ANDREA RIGONI ${ }^{* *}$
}

\author{
A PHILOSOPHICAL FRIENDSHIP \\ CIORAN AND HIS ITALIAN FRIEND MARIO ANDREA RIGONI
}

Alberto Pinzón León ${ }^{* * *}$

\section{Resumen}

* Artículo de investigación, cedido especialmente para este número.

** Uno de los grandes escritores italianos del siglo XX. Falleció en el 2008, profesor de literatura en la universidad de Padua, editor de la obra de Leopardi, editor y traductor de la obra de Cioran en Italia. Las huellas de su amistad se evidencian en Mon cher ami, lettere a Mario Andrea Rigoni 1977-1990, (il notes magico, Padova, 2007). Texto que muestra el lado más humano y cotidiano, es decir, lo más íntimo de Cioran, en relación con el cultivo de la amistad; pero por otro lado, la penetración y aceptación de su obra en Italia. Mario Andrea Rigoni poeta, ensayista y un representante de la literatura aforística italiana, obras como $L a$ pensée de Leopardi (Bompiani, con prefacio de Cioran, 1977). Saggi sul pensiero leopardiano (con prólogo de Cioran, titulado "La supremacía del hastío", que se encuentra en los Ejercicios de admiración y otros textos, p. 174). Los dos volúmenes, el primero Variations sur l'impossible (trad. Franç. M. Orcel, L'Alphée, 1986) el segundo, Éloge de l'Amérique (trad. Franç. M. Orcel, Le Capucin, 2002) dan muestra de la calidad literaria de Rigoni. En relación con Cioran fuera de la ya mencionada correspondencia Mon cher ami, una pequeña colección titulada: Fascinazione della cenere (Il Notes Magico, 2005) que son unos "ejercicios de admiración a la luz de las cenizas", -como escribe su editor, es tal vez la forma más radical y clara de conocimiento- que realiza Cioran entre 1954 y 1991, publicados la mayoría en Ejercicios de admiración y otros textos (Tusquets, Barcelona, 1992). Y la obra que será motivo de nuestra reflexión In compagnia di Cioran (Il Notes Magico, 2004), es un "ejercicio de admiración" sobre Cioran, traducida al francés con el título: Cioran dans mes souvenirs ((trad. Franç. M. Orcel, P.U.F., 2009) en la que se recoge algunos artículos y se agregan otros.

*** Licenciado, Magíster, doctorado en Filosofía. Profesor Universidad Católica. 
El artículo muestra las relaciones de amistad que se van tornando en reflexiones filosóficas entre Cioran y el escritor italiano Mario Andrea Rigoni, a partir de su obra: Cioran dans mes souvenirs. Nuestro interés está en dar a conocer las reflexiones que hace Rigoni sobre la obra y el carácter humano de Cioran.

\title{
Palabras clave
}

Amistad filosófica, libertad, antisemitismo, el poder y la muerte.

\begin{abstract}
This paper shows the relations of friendship that turn into philosophical reflections between Cioran and the Italian writer Mario Andrea Rigoni, from his work: Cioran dans mes souvenirs. Our interest is to show the reflections Rigoni makes on the work and the human character of Cioran
\end{abstract}

\section{Keywords}

Philosophical friendship, freedom, anti-Semitism, power and death.

\section{Introducción}

Es a comienzos de los años setenta que Rigoni conoce a Cioran en una cena con unos amigos parisinos: no era por entonces una celebridad. Aunque había sido referenciado por Gottfried Benn, traducido por Celan y también por $\mathrm{Au}-$ den en una antología de aforismos. Sus libros publicados apenas en editoriales marginales eran reconocidos en los medios literarios por el carácter sombrío de sus escritos. Así que, cuando le presentan a Cioran, solo reconoce su nombre como un escritor entre otros. Le asombra su discreción, el tartamudeo que pareciera favorecer al chorro de aforismos, ocurrencias y fórmulas, pero sobre todo, la cantidad y la naturaleza de sus lecturas: diarios, correspondencias, biografías, memorias, retratos, autores olvidados. Confiesa que la deuda con este elegido de la melancolía, con este enamorado de las cenizas ${ }^{1}$, es una deuda

1 Cioran ha confesado su fascinación por la ceniza. Después de la incineración de un amigo y mientras abandona el cementerio, piensa si incomunicable. Cioran mezcla la sensibilidad de un desollado con la sutiliza de un sofista, con sus paradojas e hipérboles logra un contagio vital, un contagio para reír de todo, nos comenta Rigoni (Rigoni, 2009: 22).

\section{Los inicios de una amistad}

Desde la primera conversación siempre hablaron de libros más que de cuestiones teóricas. Cioran un gran lector, conocedor del alemán, francés, inglés - que lo aprendió de su compañera Simone Boué, profesora de inglés en el Liceo- rumano, húngaro, español y leía el italiano. Poseía una pequeña biblioteca,

éste no sería el espectáculo que un día debía el universo ofrecernos: la ceniza como el secreto y el desenlace de todo. Un secreto que lo sabemos desde siempre pero para olvidarlo se inventaron las religiones (Cioran, Hechizo de la ceniza, 1992b: 209). 
tomaba prestado los libros de la Biblioteca Nacional. Leía y releía de todo según una orientación y un instinto preciso. Entre los géneros preferidos encontramos, primero, las biografías, como la de Constantin Christomatos sobre "Sissi", la emperatriz de Austria; como la de Simon Leys, de Talleyrand; segundo, las memorias, sobre el tema escribió: El aficionado a las memorias (Cioran, 1995: $1417 ; 21)$. En este género en las memorias se destaca la forma literaria del "portrait", del retrato, de la semblanza, o lo hace él mismo aquí o allá en sus ensayos, o haciendo una antología, como en Anthologie du portrait littéraire de Saint Simon à Tocqueville (1996). Tercero. Otro de los géneros es la lettre, la carta: sobre el asunto escribió el texto Manie épistolaire: "La carta, conversación con un ausente, constituye un acontecimiento capital de la soledad. La verdad sobre un autor debe buscarse en su correspondencia y no en su obra. La obra es con frecuencia una máscara" (Cioran, 1992b: 205). ¿Qué poseen de común estos géneros? Son expresiones personales, el testimonio o la reflexión vital de un yo. Son géneros que expresan sin intermediarios una realidad vital, ya que “... todo lo que no es directo es nulo” (Cioran, 1995: 751; 1980: 6).

Cioran no pretende ser un filósofo original, pues no hay allí filosofía, ni originalidad, sino una pizca de ingenio; condición necesaria para un autor que surge en plena decadencia de Occidente y que anhela, no ser un historiador, sino un profeta del fin de la historia. En el apartado titulado Contamination totale, epílogo a la edición Italiana de Histoire et utopie, Rigoni anota: "El único pensador de nuestro tiempo que se niega a toda fórmula, a toda categoría, e incluso a toda clase de profesionalismo intelectual, que expresa por escrito la condición misma del hombre completamente desilusionado; errante entre la sabiduría, la tragedia y la farsa" (Rigoni, 2009: 35).

\section{Un amigo que reflexiona sobre Cioran a través de sus obras}

La obra de Cioran, un gran Breviario de podredumbre, una suma de lo Imposible y lo Incurable, más que una creación, es un precipitado de conciencia, que no se inspira en Platón, Kant, Hegel, Marx, Freud, Heidegger o incluso en Nietzsche; sino en Buda, en el Eclesiastés, en los Cínicos, los Escépticos, los Gnósticos de la antigüedad, en Tácito y Maquiavelo, Swift y Mme du Deffand, Pascal y los moralistas franceses, en los poetas y escritores que no son únicamente grandes artistas, de Shakespeare a Baudelaire, de Leopardi a Dostoievski. Es decir, en todos los desertores del orden, de la norma, de la impostura existencial y social, de los herejes a los suicidas, de los místicos a los vagabundos. Cioran busca lo que une los elementos dispares de la lucidez, con la invención de un lenguaje que disipa la apariencia y va sobre lo esencial, el aforismo. Un hombre rumano emigrado a París, acostumbrado a todas las decadencias guarda el frescor de la barbarie, que favorece su vocación por los extremos, su capacidad de unir el desprendimiento con la desmedida, la elegancia y la modestia, la sutilidad y el exceso, viene de una experiencia de contrastes que solo alcanza un espíritu que toca lo real, remata diciendo Rigoni (2009: 37).

Rigoni se detiene en ese polémico texto político de Cioran, Essai sur la pensée réactionnaire, donde aplica a la política el principio satánico según el cual “todo progreso implica un retroceso, toda ascensión una caída... Lo trágico del universo político reside en esa fuerza oculta que conduce a todo movimiento a negarse a sí mismo, a traicionar su inspiración original y corromperse a medida que se arma y avanza. Porque en política, como en todo, nadie se realiza sino a través de su propia ruina" (Cioran, 1995: 1545; 1992a: 
46). De esta manera la revolución no se distingue de la reacción que combate hasta el momento en que ella se realiza, es decir, al tiempo que sigue siendo una virtualidad y una abstracción.

...una revolución que ha triunfado y que se ha instalado, que se ha convertido en lo contrario de una fermentación y de un nacimiento, deja de ser una revolución, e imita y está obligada a imitar las características, el aparato y hasta el funcionamiento del orden que ha derrocado; cuanto más se consagra a ello (y no tiene más remedio que hacerlo), más destruirá sus principios y su prestigio. Conservadora en adelante a su manera, luchará, no para defender el pasado, sino el presente. Nada la ayudará tanto como seguir las vías y los métodos que usaba para mantenerse el régimen que ha abolido (Cioran, 1995: 1544, 44-45).

Historie y Utopie es publicada en 1960, pero los dos primeros ensayos datan de 1957, justo después de la revuelta húngara de 1956. Está compuesta de seis ensayos, que revisan las paradojas terribles que enfrentan a cada paso la reflexión moral y política. Una reflexión sobre la psicología y la dinámica del poder, "bajo una ley perversa e inexorable inscrita en la naturaleza misma del ser, que asocia el espíritu a la enfermedad, la conciencia a la esterilidad, la civilización a la decadencia, la sabiduría y el equilibrio a la inanidad, como al contrario la salud a la par con la barbarie, la fecundidad con la imprudencia, el porvenir con el instinto, la eficacia con el desequilibrio y la demencia", afirma Rigoni (Rigoni, 2009: 41).

Pero el problema está en la libertad, sin ella no se puede vivir, pero cuando se encuentra con ella lo que viene a faltar es la vida misma.
La libertad... exige el vacío para manifestarse; lo exige y sucumbe en él. La condición que la determina es la misma que la anula... El hombre está tan poco hecho para soportar la libertad, o para merecerla, que incluso los beneficios que de ella recibe lo aplastan, y termina por sucederle hasta tal punto que prefiere sus excesos a los excesos del terror... la libertad, frágil ella misma, no tiene ningún medio para mantenerse $\mathrm{y}$ sobrevivir a los peligros que desde dentro y desde fuera la amenazan; además, sólo se manifiesta a la sombra de un régimen agonizante, en el momento en que una clase declina y se disuelve... Las libertades sólo prosperan en un cuerpo social enfermo: tolerancia e impotencia son sinónimos. La libertad... Huye de nosotros en el momento mismo en que tratamos de aprehenderla y formularla: nadie puede gozar de ella sin temblor. Desesperadamente mortal, en cuanto se instaura postula su carencia de porvenir y trabaja, con todas sus fuerzas minadas, en negarse y agonizar (Cioran, 1995: 987-988; 1988a: 31-32).

De ahí que frente a la anemia, a las perplejidades y a los escrúpulos autodestructivos de las democracias occidentales, se alcanza un grado de civilización, de refinamiento y complejidad que "sólo se sobrepasa descendiendo". El Imperio ruso condenado a la ascensión;

Con sus almas modeladas en las sectas y en las estepas, da una singular impresión de espacio y encierro, de inmensidad y de sofoco, de norte, en suma... Mientras más se humaniza un imperio, más se desarrollan en él las contradicciones que lo harán 
perecer $[\ldots]$ ¿Hacia dónde te apresuras de esta manera, oh Rusia?, se preguntaba Gogol, que había percibido el frenesí que se escondía bajo su aparente inmovilidad. Hoy sabemos hacia dónde corre, sabemos sobre todo que, a imagen de las naciones con destino imperial, está más impaciente por resolver los problemas ajenos que los suyos propios. Es decir que nuestra carrera en el tiempo depende de lo que decidirá o llevará a cabo: tiene entre sus manos nuestro porvenir (Cioran, 1995: 1001-1004, 54 у 60).

Cioran desilusionado del comunismo como de la democracia, capaz como nadie de elegir las contradicciones a la vez opuestas y simétricas, y dividido entre la apología de una afirmación vital desnuda de prejuicio y una sabiduría trágica que sabe ver en el soplo vital un preludio al fanatismo y a las catástrofes, realiza esta premonición hace 25 años cuando Rusia era para todo el mundo objeto de culto o de condenación, igualmente erróneas porque estaban dictadas por puras y ciegas ideologías. La única y débil esperanza que les queda a los europeos sería que los rusos se dejarán atraer y contaminar por su democracia, por las seducciones de su crepúsculo. En tal caso, "se civilizarán a expensas de sus instintos, $y$, perspectiva regocijante, conocerán también el virus de la libertad" (Cioran, 1995: 1001, 55).

Rigoni afirma, que la fascinación que ejerció Rusia sobre Cioran se ha disipado, puesto que la degradación de las cosas, el instinto en sí mismo ha dejado de ser una promesa, la barbarie en sí misma está desprovista de las últimas sombras de prestigio y grandeza. Sólo queda el movimiento real de la historia, el más simple acontecimiento hunde sus raíces en una fuerza insaciable. Los regímenes liberales o democráticos, no develan sino variaciones de intensidad de un mismo apetito de poder, un apetito que conducirá a una tiranía planetaria. El apetito de poder no podrá ser extirpado de la política y, más generalmente, de la historia, pues está en el corazón mismo del actuar y es consecuencia directa de la falta original, de la fractura de lo absoluto. Sustraerse al apetito del poder, significa abdicar a la existencia misma, al mundo del individuo, a la posibilidad de ser o de llegar a ser, en cualquier lugar en cualquier forma algo o alguien.

El poder en su forma más odiosa pero también más natural, la tiranía política o espiritual, es un imperativo demoniaco que determina toda manifestación humana, incluso la piedad de los santos, esta sutil perversión, "este vicio de la bondad". Uno no se conserva, no obra, no produce sino en la fuerza y fecundidad del mal. "Para dar el menor paso hacia adelante se requiere un mínimo de bajeza, incluso para subsistir" (Cioran, 1995: 1028, 104). Todas las formas de eficacia, de rendimiento y de realización en el mundo provienen de regiones inferiores del yo, de sentimientos innobles, de las más viles reacciones, en particular los celos y la venganza que Cioran eleva a principio cosmológico; sin la fuerza del mal no habría acontecimientos, ni incluso mundo. De esta fiebre no se escapa ni Dios - Satán, maestro del tiempo, no es más que el rostro visible. En fin, actuar es la negación y la pérdida de la edad de oro de las utopías antiguas y modernas.

Un monstruoso contrasentido es buscar mediante un acto recrear la felicidad sobre la tierra, conjugar el sueño del paraíso con la maldición del futuro. Más sin embargo, este contrasentido teje la trama de nuestro destino, donde la esperanza no puede ser separada del horror, el progreso del mal estado, la utopía del apocalipsis. Si hubiera una salvación o alguna redención, ella jamás vendría del mundo histórico-reino de la abyección dinámica-, sino del redescubrimiento del "principio intemporal de nuestra naturaleza" de la percepción interior de un eterno presente que se arrebata al devenir 
y a la misma eternidad, del cual Dios no sería más que la repetición superflua.

En el descendimiento en el infierno del actuar, se escruta y describe en una perspectiva que participa a la vez de la fisiología y de la gnosis - posiblemente las únicas claves que permiten penetrar en los fenómenos- terminando en una escatología solitaria y negativa, igualmente liberada del infierno de la historia y de los paraísos artificiales de la utopía y de la teología. Un apocalipsis tanto más significativo que surge de un espíritu nunca inclinado a la ascesis, pero que percibe hasta la convulsión inútil de decirlo, la apelación y la fatalidad del acto. El pensamiento cioraniano recorre el anverso y el reverso de toda manifestación, que revela la subyacente complicidad de los contrarios, que coloca al desnudo la inextinguible duplicidad de lo real, con el único resultado de terminar en un círculo vicioso y, por tanto, en la irresolución absoluta.

En el capítulo dedicado al Breviario de Podredumbre titulado: Vérite du moi, Rigoni muestra como el Breviario - primer texto escrito en francés por Cioran, en 1949-, es una obra que por aquella época no podía ser bien recibida en la atmósfera intelectual francesa, entre otras cosas por su anti-historicismo, porque para Cioran: "La historia es un desfile de falsos absolutos, una sucesión de templos elevados a pretextos, una degradación del espíritu ante lo Improbable" (Cioran, 1995: 581; 1977: 19). Es un texto contra la tradición filosófica francesa y en general contra la tradición filosófica, heredera de los moralistas franceses, de Pirrón, de Pascal, del Eclesiastés. Una obra en la que no se expone un sistema filosófico sino el fin de todos los sistemas, en la que no se profesa una fe sino la mentira y el peligro de todas las fes, que no ilustra una idea sino la podredumbre de todas las ideas. En el plano gnoseológico, se inclina por el derecho imprescriptible de la subjetividad y no por la impersonalidad del concepto, por la verdad concreta y orgánica del yo y no por la abstracción del razonamiento.

Desde el primer libro Sur les cimes du désespoir, Cioran ya planteaba esta perspectiva: "Amo el pensamiento que guarda un sabor a sangre y carne, prefiero mil veces a la abstracción vacía una reflexión nacida de la sensualidad o de un colapso nervioso (...) más revelador es un grito de desesperación que la más sutil de las argucias, una lágrima tiene fuentes más profundas que una sonrisa" (Cioran, 1995: 32; 1991: 44). Aunque desde esta primera obra hay un énfasis desbordado en el lirismo, puesto que el lirismo es una efervescencia incontrolable que busca la expresión, por eso uno se vuelve lírico en el sufrimiento y en el amor, porque esos dos estados surgen de la profundidad del ser, del nervio íntimo de la subjetividad.

Nos volvemos líricos cuando la vida
interior palpita a un ritmo esencial
[...] Sólo se vuelve uno realmente
lírico tras un profundo trastorno or-
gánico [...] el estado lírico está más
allá de las formas y de los sistemas
[...] el lirismo es una expresión
bárbara; su verdadero valor consis-
te, precisamente, en no ser más que
sangre, sinceridad y llamas (Cioran,
1995: 20-21. pp. 15, 16 y 17).

Es en el Breviario donde se da el encuentro entre la lucidez y lirismo.

En su opera prima publicada en 1934 en Bucarest, Sobre las cimas de la desesperación, se puede observar una gran afinidad en su estructura, temas y ritmo febril con el Breviario, la cual se puede considerar como su anticipo o su prototipo. Tanto en su primera obra como en el Breviario, están organizados por capítulos filosóficos con tonalidad fuertemente subjetiva y de carácter aforístico. 
Existiendo una gran analogía con La Gaya ciencia o Aurora de Nietzsche. Así como, las meditaciones del Breviario evocan los Petits poèmes en prose de Baudelaire. Sin embargo, Rigoni se lamenta, que Cioran tan afín a Baudelaire, no se haya pronunciado al respecto, podría haber encontrado en $L e$ Spleen de París su modelo formal, como Baudelaire reconoce el suyo en Gaspard de la Nuit de Bertrand.

El Breviario pretende disolver la historia del pensamiento, incluso la historia como tal. Es una recensión de todas las enfermedades, una concentración de todos los venenos, una síntesis de todas las decadencias del espíritu. Este libro que nació con el nombre de Exercises négatifs ${ }^{2}$ (Cioran, 2005: 179), fue reescrito tres veces en 1947. El término Exercises, reaparecerá con ese sentido de auto-reflexión irónica de la conciencia, en su obra Exercises d'admiration. En el Breviario Cioran se juega todo, está todo allí. Su tonalidad tan singular no se repetirá en sus otras obras, aunque sí su desarrollo temático.

A partir de 1949 Cioran escribirá ensayos y aforismos, el Breviario no se identifica con ninguno de estos géneros, aunque comparte algunas de sus características; mezcla y funde de manera radical el análisis y la confesión, la objetividad y el espasmo, la claridad y el furor. Cioran confiesa que después del Breviario, tiende hacia la aridez y la melancolía. Sin negar el valor de sus otras obras, el Breviario tiene un espíritu imaginario y lingüístico que Rigoni compara con Shakespeare, o con un

2 Édition avec postface, établie et annotée par Ingrid Astier. Nota 1 en la página 179. Se encuentran muchos manuscritos del Précis de décomposition. (Cioran declaró haberlo re-escrito cuatro veces). El que citamos acá se encuentra en la Biblioteca literaria Jacques Doucet, este manuscrito es muy dispar, compuesto por 447 páginas, el papel utilizado por Cioran es de formato variado, privilegia la tinta negra, pero se encuentra igualmente tintas azul y verde. libro bíblico. No se puede encontrar una obra en el siglo XX, en que haya tal alianza entre abstracción y carne, entre filosofía y sangre, entre el concepto y el alma, al servicio de las acusaciones más tempestuosas o las más puras a la vez, que se hayan escrito contra el hombre, la vida, el mundo, la civilización, en una palabra contra el Ser, incluso contra lo posible. El Breviario, es como un evangelio secreto de nuestra experiencia intelectual, afirma Rigoni. Es la "summa" de su obra, como puede ser la "summa" del siglo XX o de la modernidad.

En el capítulo La Littérature et la nuit de l'âme, Rigoni aborda los Cahiers ${ }^{3}$ (Cioran, 1997: 9). Estos cuadernos inéditos hasta su muerte, no constituyen solamente un material interesante desde el punto de vista biográfico o filológico, sino un verdadero libro, -a pesar de sus repeticiones y la coincidencia con aforismos ya conocidos- transmite el sentido de una aventura intelectual. Estas casi mil páginas dan razón del insensato juego del escribir -como decía Mallarmé-, de las angustiantes reflexiones que supone el ir tomando estilo, hasta convertirse en un discurso con su propio tono. En diciembre de 1969 escribe:

3 Avant-propos de Simone Boué, p. 9: "Durante mucho tiempo hubo sobre la mesa de Cioran un cuaderno cerrado. A su muerte, al reunir sus manuscritos para entregarlos a la Biblioteca Doucet, encontré treinta y cuatro cuadernos idénticos. Sólo diferían las tapas, marcadas con un número y una fecha. Comienzan el 26 de junio de 1957 y se interrumpen en 1972". Sobre estos textos Cioran nunca hizo alguna referencia, es gracias a su compañera Simone Boué-seguro contra la voluntad de Cioran-que le debemos la conservación y edición de estos cuadernos. Son verdaderos "cuadernos de ejercicios", de proyectos, de esbozos; donde retoma una misma reflexión hasta tres o cuatro veces de forma diferente, buscando pulirla, abreviándola, encontrando la máxima concisión. 
Voy a aferrarme a estos Cahiers, pues son el único contacto que he tenido con la "escritura" [...] este ejercicio cotidiano tiene de bueno, que permite acercarse a las palabras y descargar mis obsesiones, al mismo tiempo que mis caprichos [...] pues no hay nada más deshidratante y más fútil que la persecución de una «idea» (Cioran, 1997: 11).

La brillantez literaria del estilo de Cioran es una de las características más visibles y, por ello, es considerado uno de los más grandes escritores del siglo XX; pero esto, es fruto de una maestría retórica; de reflexiones espontáneas, de confesiones íntimas, de diálogos consigo mismo. Los Cahiers ${ }^{4}$ es un libro sin destinatario y sin público, que no disminuye en nada el pensamiento y el talento del escritor, que se encuentra sumergido en la fuente viva y personal de su experiencia. Cioran ataca la jerigonza filosófica, odia los tecnicismos, práctica un lenguaje común que se complejiza en su propia reflexión. Nunca recurre a un artificio verbal, a un lenguaje de moda, de academia, o incluso a un cálculo estilístico. Aquí uno descubre mejor que en ninguna otra parte, al hombre Cioran: un hombre a la vez torturado y escéptico, modesto y explosivo, sin ninguna ilusión por el mundo, ni por sí mismo, ni por sus obras que no le hacen ninguna gracia.

Para Cioran la crítica literaria es superflua, la considera la más fútil, la más estéril, "es mejor ser tendero que escribir sobre los otros" (Cio-

4 La traducción al español contiene muchos errores. No respeta por ejemplo las fechas de la edición francesa y la traducción no es la mejor. Los textos fueron seleccionados por Verena von der Heyden-Rynsch, con el criterio, dice ella, de veinte años de amistad y de una larga experiencia como traductora de su obra al alemán. Pero me parece que es una edición de 265 páginas muy descuidada y no sigue ningún criterio para seleccionar los textos. ran, 1997: 504). Desconfía profundamente de la literatura, por temor a que la fatalidad de una experiencia no se degrade en una pose, en una búsqueda de efecto, en un simple ejercicio, en una palabra que no sucumba a la mentira del arte. Hablando de Fitzgerald, Cioran considera que es propio de un espíritu de segundo orden, no saber elegir entre la literatura y la verdadera noche del alma.

Los Cahiers, son la verdadera noche de su alma. Es la lucha contra las apariencias, lágrimas derramadas sobre la vacuidad universal, sobre la desventura de haber nacido; ello no demeritan la batalla intelectual realizada por Cioran: la precisión del diagnóstico histórico, psicológico, moral e incluso literario realizado.

\section{Cioran y Leopardi sus dos entrañables ídolos}

En los siguientes capítulos Rigoni compara sus dos ídolos: Cioran y Leopardi. Encuentra en primer lugar una afinidad en la estructura de los Cahiers y Zibaldone di pensieri de Leopardi, en ellos hay una multitud de notas, de esbozos y reflexiones, acumuladas durante quince años, en un comienzo estrictamente privado, no solamente como una fuente importantísima para esclarecer su obra publicada, sino su aparición como una obra como tal. Estas notas póstumas son en realidad la biografía secreta, son la novela intelectual y metafísica que todo escritor ha querido escribir. Expresión directa de un yo herido, en forma de fragmentos, porque Cioran como Leopardi se sienten como astillas de una totalidad perdida. Ambos reconocen que nunca han escrito una obra, que solo han escrito ensayos, que el fragmento les viene bien; es en efecto el estilo que se adhiere mejor al hombre moderno, que se sustrae a la tiranía de la idea y a la falsedad del sistema. Los escritores de este estilo son cautivados por la existencia, los seres y las cosas, no por las filosofías, las escuelas o los métodos. Inmersos en lo esencial, atraídos por la fisiología y la metafísica, extraños a 
las jerigonzas y a las modas, se encuentran más cerca al conserje o la prostituta (Cioran, 1995: 651; 1197: 97), que a los críticos o a los académicos.

Luego encuentra que los dos pensadores se expresan de idéntica manera. En los Cahiers, Cioran escribe: "Si todo es ilusión, no hay nada más real que la ilusión" (Cioran, 1997: 282), mientras que Leopardi anota en $\mathrm{Zi}$ baldone: "Parece absurdo y sin embargo es exactamente verdadero que, todo lo real es nada, y no hay nada más real y substancial en el mundo que las ilusiones" (Rigoni, 2009: 64). Cercanos por su comportamiento, lo son por sus convicciones extremas, no los une cualquier filiación sino que pertenecen a una misma familia espiritual, por ejemplo, en cuanto a la irrealidad del mundo y, por tanto, a la paradójica sustancialidad de la ilusión. Es precisamente de este nihilismo, no desprovisto de una coloración religiosa, que en los Cahiers deriva en una extraordinaria vitalidad: obsesiones, confesiones, execraciones, juicios sobre autores, sobre amigos, sobre duelos familiares, sobre enemigos jamás nombrados, a excepción de Lucien Goldmann ${ }^{5}$ uno de sus más tenaces perseguidores.

Rigoni reconoce que su amistad con Cioran no nació bajo el signo de Leopardi, pero si su correspondencia bajo sus auspicios. Mario Andrea Rigoni publica Leopardi et l'esthétisation de l'antique, se lo envía a Cioran y en carta fechada el 18 de marzo de 1977, le comenta

$5 \quad$ "Mi enemigo más encarnizado que no deja de calumniarme desde hace más de veinte años. Ha creado un vacío a mi alrededor, los críticos que me apoyaban me odian, ninguna revista me solicita colaboración. Él me ha impedido entrar en la investigación, me ha hecho perder más de un amigo. Y sin embargo le debo mucho. Sin su campaña de denigración, todo habría sido fácil para mí, tendría hoy un nombre, es decir que yo sería un cadáver. Tal vez lo soy, pero de otra manera, más honorable, el menos desde mi opinión" (Cioran, 1997:. 457). que realmente ha vuelto sobre Leopardi a intervalos muy espaciados, aunque su Lebensgefühl le es peligrosamente cercano. Además elogia el libro de Rigoni y concluye que el pensamiento de Leopardi es más un problema de estilo que de conocimiento. Y hacia el final de la carta le anuncia que le enviará Syllogismes de l'amertume, que según Cioran son una serie de bromas entre la interjección y la "total indiferencia a la verdad -citando a Leopardi- que es el estado natural de nuestro primer ancestro" (Rigoni, 2009: 72-73).

Rigoni reconoce que, desde la primera carta aparecen ya dos temas que destacará más tarde en su prefacio, "Un mot sur Leopardi", a una colección de ensayos leopardianos. Estos dos temas son: el reconocimiento de una afinidad profunda con Leopardi-hasta un exceso de proximidad en su concepción sobre la existencia- y la confesión, coloreada de un cierto lamento, de tener un conocimiento parcial de su obra.

En las cartas referenciadas por Rigoni se observa cómo Cioran le confiesa su afinidad con el pensamiento de Leopardi:

- carta del 6 de septiembre de 1979, Cioran dice: "nada de cuanto concierne a Leopardi me es extraño, todo lo que toca a la individualidad, a la infinitud y a la conciencia me concierne".

- carta del 2 de noviembre de 1981. Cioran escucha a Brahms y se repite cada día la frase de Leopardi "la terrible y bárbara alegría de la desesperación", es posible se pregunta Cioran que sea la fórmula que experimento y pienso.

- carta fechada el 8 de julio de 1982, después de la lectura de las Variations sur l'Impossible y los ensayos sobre el pensamiento de Leopardi (1985), da lugar a esta nueva carta, centrada sobre el tema de la ilusión, y la afinidad entre Leopardi y el budismo. Cioran anota, "yo vivo día y noche con esta palabra (ilusión), y la digo y repito a propósito de todo lo que sucede”. 
Continúa diciendo que "se ocupa de Leopardi porque está muy próximo a él, como al Eclesiastés" (Leopardi, 1985: 74-75). Le comenta a Rigoni que debe comprender su interés por los antecedentes filosóficos de Leopardi: de sus tentaciones contradictorias entre materialismo y platonismo, el papel capital que juega en él, el Iluminismo, de la profunda afinidad entre Leopardi y Buda, y de su visión nihilista de inspiración materialista duplicada por una aspiración metafísica: "Por un lado, todo es agregado, luego nada; por otro, el nirvana es a la vez todo y nada ${ }^{6}$ ". Cioran comparte con Rigoni el rechazo a la interpretación "progresista" del pensamiento de Leopardi, que había invadido toda la crítica italiana.

Se abre un nuevo capítulo en la amistad entre Cioran y Rigoni cuando descubren la presencia, hasta ahora ignorada, pero intuida por Leopardi de carácter histórico-política, sobre la amenaza que representa Rusia en el futuro anotada en La strage delle illusioni ${ }^{7}$. Por ello, Cioran le explica en Carta del 11 de julio de 1983, entre otras cosas, la actitud complaciente de Hegel frente a Rusia, si se piensa en las excelentes relaciones entre Prusia y el imperio de los zares, - la armada rusa había sido construida sobre el modelo prusiano-. Cioran le señala a Rigoni, que no hay que olvidar que Catherine era alemana, que Paul I era loco por todo lo teutónico, y que los Romanov fueron distinguidos para bien o para mal por los germanos. Y que la mujer de Nicolas II fue la última representante

6 Es una traducción libre: "D'un côte, tout es agrégat, donc rien; de l'autre, le nirvana, qui est à la fois rien et tout" (Cioran, 1997: 76).

7 Adelphi, Milano, 1998. Este texto es una profunda reflexión de carácter histórico político, poco conocido, pero de la talla de un Maquiavelo o de un Tocqueville. Escruta con una lucidez radical el cuerpo monstruoso de la sociedad y de la historia. Es una visión negativa de la historia, una crítica del progreso y de la civilización, no desde una óptica racionalista, moral o teológica. En fin, es una visión desesperada y desalentadora del fin de Europa. de estos cursos alemanes a los cuales asistían las princesas rusas. Ella lleva gran parte de la responsabilidad del hundimiento del imperio. Para volver sobre Hegel, no hay que olvidar el gran número de aristócratas rusos que frecuentaban sus cursos, que una vez penetraban en su país, se adherían a sus ideas. Él no se dio cuenta del peligro que representaban estos entusiastas rusos para el viejo mundo. Le anuncia que le enviará una biografía sobre Nicolas I y el libro de Custine, el libro más profético sobre Rusia, Una pesadilla espléndida, y agrega a Leopardi le hubiera gustado.

Rigoni recibe el libro de Custine, Lettres de Russie y sobre la cubierta del libro a lápiz lee: "Querido amigo, si Leopardi hubiera vivido seis años más habría podido leer este libro, (aparecido en 1843) que le da la razón. Amistad y buena suerte se necesitan para afrontar estas páginas" (Rigoni, 2009: 79).

El retrato que Cioran hace de Leopardi, se puede resumir en una carta del 3 de agosto de 1987 que vuelve sobre el tema, el fin de Europa. "La lucidez política de Leopardi es asombrosa (...) Lo que no sabíamos del porvenir de Europa, Leopardi ya lo sabía. Obviamente, estamos perdidos" (Rigoni, 2009: 79-80).

Cada vez se puede observar más la coincidencia entre Cioran y Leopardi, anti-racionalista, anti-humanista, anti-historicista, por la idea de existencia como ilusión, por la conciencia de la destructividad intrínseca del pensamiento, por el culto a la antigüedad y al estilo, por la percepción de la decadencia, y del fin de la historia. Rigoni para enfatizar más esa afinidad, cuenta una anécdota que una vez paseando los tres con Michel Orcel, especialista en Leopardi, Cioran con cierto sarcasmo exclama: ¿Leopardi me ha plagiado!

Tanto Cioran como Leopardi, comparten la experiencia capital del "ennui", del hastío, es decir, de la vacuidad universal de las cosas que 
perciben no sólo a nivel del pensamiento sino de su propia carne. Los dos eran escépticos radicales hasta el extremo de no contar con alguna "ilusión", aunque la hayan reconocido como necesidad para la vida y para la historia. Ambos piensan que el hombre es un animal tarado desde sus orígenes y que, habiendo abandonado su camino natural al punto de convertirse en una amenaza, marcha inexorablemente hacia su propia destrucción. Esta es la causa primera de su anti-humanismo y antihistoricismo radical. Uno y otro son maestros de la lucidez - una cualidad que no es útil para la vida- y del escepticismo -el mejor antídoto para la violencia-. Ambos hablan del suicidio, Cioran para afirmar que gracias a la idea del suicidio él no se suicidó, mientras Leopardi medita sobre el suicidio desde la edad de 20 años, lo hace tema de su reflexión y de su poesía.

Pero también hay una diferencia psicológica e histórica entre los dos escritores: en Cioran, heredero e intérprete de todas las decadencias, hay una genialidad en la exageración, en la hibridación y en la teatralidad irónica, que es extraña a la pureza clásica de Leopardi. Se podría decir que Cioran está más cerca de Baudelaire, uno de sus autores preferidos. En últimas, la diferencia entre Leopardi y Cioran, es la diferencia entre un clásico y un epígono. $\mathrm{Su}$ afinidad llega a tal punto que escriben de manera aforística convirtiéndose en los mejores de esta tradición.

Aunque podemos encontrar también una cierta similitud entre el pesimismo de Rigoni y el de Cioran. El pesimismo de Rigoni es de carácter metafísico, es decir, en la expresión "la existencia es demasiada siniestra para que no haya detrás algo", hay una búsqueda de un fundamento que salve la existencia de alguna manera de su fatalidad, un "posible", en cambio en Cioran su pesimismo, es un pesimismo sin más allá, sin perspectiva, sin futuro, sin un sustrato que lo justifique.

\section{Rigoni desmiente el antisemitismo de su amigo Cioran}

Rigoni reflexiona en el siguiente capítulo "Sur le passé politique du Cioran", que si bien es cierto sorprende la actitud de Cioran al simpatizar con el fascismo rumano de los años treinta, ello se puede comprender hasta cierto punto. Ya que no hay que olvidar que un número importante de pensadores, artistas y escritores del siglo XX, aunque en diferentes grados, se adhirieron al fascismo y al nazismo, lo que hace más complejo la interpretación de este fenómeno. "Yo diría que la naturaleza de esta elección sostiene igualmente un radicalismo sobre el pensamiento o sobre la vida, de aquellos que han caído en este error" (Rigoni, 2009: 94). Por otra parte, cabe recordar que por aquella época y décadas posteriores, la mayoría de los intelectuales europeos eran fascistas o

8 Sobre este polémico tema citaré algunos libros, el más controvertido: Laignel-Lavastine, Alexandra. Cioran, Eliade, Ionesco: L'oubli du fascisme. P.U.F., Paris, 2002; Petreu, Marta. An infamous past: E. M. Cioran and Rise of fascism in Romania. Ivan R. Dee, Chicago, 2005; Ornea Zigu. Les années 30: l'extrême droite roumaine. Fundatiei, Bucarest, 1995; Sebastian Mihail. Journal (1935-1944). Stock, Paris, 1999; Artículos tales como: Lotringer Sylvère. "Portrait d'un jeune ècrivain dans le délire hitlérien", en Cioran. L'herne, Paris, 2009: 59; Petreu, Marta. "Le problème juif dans l'oeuvre roumaine de Cioran", en Cioran. L' herne, Paris, 2009: 70; Finkenthal Michael. "Cioran et les Juifs”, en Cioran. L'herne, Paris, 2009:.81; Bradesco Faust. "Emil Cioran renié son passé", Carpatii, No. 16-17, 25 octobre-25 novembre 1973: 1; Tertulian Nicolae. "La période roumaine de Cioran", La Quinzaine littéraire, No. 351, 1er-15 juillet 1981. Obras problemáticas sobre el pasado fascista de Cioran: Cioran E. M. La transfiguration de la Roumanie. Vremea, Bucarest, 1936 (réed. 1941); Humanitas, Bucarest, 1990. Versión reeditada con supresión de pasajes y capítulos por parte del autor. Nueva edición y versión completa: L'herne, Paris, 2009. Una serie de artículos publicados entre 1931-1943 titulado: Solitude et Destin. Traduit du Roumain par Alain Paruit. Gallimard, Paris, 2004. 
comunistas, lo que la sociedad no reprocha de la misma manera. Por ello Rigoni no está de acuerdo con los planteamientos de la obra de Laignel-Lavastine, Cioran, Eliade, Ionesco. L'oubli du fascisme, lo considera un libro inquisitorial y malicioso, que insinúa sin probar, que si bien aporta unos nuevos documentos su interpretación es totalmente errónea.

Rigoni defiende de manera radical a Cioran de su pasado fascista, anotando que él ha renegado muchas veces de sus errores de juventud, que jamás ha ocultado dicho pasado como lo han hecho otros escritores de derecha o izquierda, se ha liberado de ese nefasto pasado a través de un itinerario observable a través de su obra. Según Rigoni basta leer la Genealogía del fanatismo 9 (Cioran, 1995: 581; 1977: 19) para ver con que lucidez se opone a las fascinaciones de juventud. Niega que Cioran formara parte del movimiento fascista rumano, la "Garde de fer". Quien realmente militó en dicho partido político fue su hermano Aurel, por ello fue a prisión varios años, aunque admite que Cioran si simpatizó con dicho movimiento pero en su aspecto místico.

Rigoni insiste en colocar en el mismo plano tanto el fascismo como el comunismo, en términos objetivos haber sido comunista no es menos grave que haber sido fascista o nazista, haber dedicado culto a Lenin o Stalin no es menos deshonroso que haber adulado a Hitler. La innegable diferencia original de las ideas y de los fines que opone el comunismo del fascismo o del nazismo, no justifica ni redime en nada la barbarie absoluta de sus métodos y de sus

9 Me parece más contundente -para proseguir esa línea de defensa adoptada por Rigoni, al pasado fascista de Cioran- el artículo "Mon Pays". Texto encontrado por Simone Boué en la primavera de 1994, son 11 páginas escritas en francés posiblemente en los años 50, en las que Cioran deja ver la relación tormentosa con su país y su adherencia a la extrema derecha rumana. resultados que fueron similares. Sin embargo Rigoni toma partido al afirmar que quien ha salvado a Europa del totalitarismo son los Estados Unidos, punta de lanza del liberalismo antídoto de cualquier forma de totalitarismo. $\mathrm{Y}$ agrega que todo antiamericanismo es una forma solapada del espíritu totalitario del siglo $\mathrm{XX}$ europeo y que llega a simpatizar con el fundamentalismo islámico. Por supuesto que Cioran está lejos de tal americanismo, porque además incluía a los Estados Unidos en la decadencia de Occidente.

Para Rigoni la atracción que Cioran tuvo por el fascismo se debía a la cuestión de su nacionalismo, porque amaba a su país, pero al mismo tiempo veía el estado lamentable en que fue arrojado a la historia. Un ejemplo contundente lo podemos encontrar en la "Pequeña teoría del destino":

Creía, y quizá no me engañaba, que habíamos surgido de la hez de los bárbaros, del desecho de las grandes invasiones, de esas hordas que, incapaces de seguir su marcha hacia el Oeste, se desplomaron a lo largo de los Cárpatos y del Danubio, para acurrucarse ahí, para dormitar, masa de desertores en los confines del imperio, chusma maquillada con una pizca de latinidad. De tal pasado, tal presente. Y tal porvenir. ¡Dura prueba para mi joven arrogancia! « ¿Cómo puede serse rumano?», era una pregunta a la que yo no podía responder más que por una mortificación de cada instante. Como odiaba a los míos, a mi país, a sus campesinos intemporales, encantados con su torpor y se diría que deslumbrantes de embrutecimiento, yo me avergonzaba de ser su descendiente, renegaba de ellos, me rehusaba a su infra-eternidad, a sus certidumbres de larvas petrificadas, a su soñarrera 
geológica. Era inútil que buscase bajo sus rasgos el azogamiento las muecas de la rebelión: el mono, ay, se moría en ellos. A decir verdad, ¿acaso no propendían más bien a lo mineral? No sabiendo cómo zarandearlos, cómo animarlos, comencé a soñar con su exterminación. Pero no se puede hacer una matanza de piedras. El espectáculo que me ofrecían justificaba y desviaba, alimentaba y desanimaba mi histeria. Y no dejaba de maldecir el accidente que me hizo nacer entre ellos (Cioran, 1995: 847; 1988b: 43).

Según Rigoni este drama psicológico lo explica todo. Cuando Cioran vivió en Alemania entre los años 33 y 34 , ve con qué velocidad y eficacia el nazismo re-direcciona y organiza el pueblo alemán y pensaba que una solución análoga podría salvar a su Rumania del alma. Dicha visión se fundamenta según Rigoni en la admiración de Cioran por los tiranos en general. Como lo prueba su admiración por Lenin, por el Capitán Coodrenau o cualquier otro dictador, evidenciado en La escuela de los tiranos ${ }^{10}$.

Rigoni niega el antisemitismo de Cioran, lo plantea como una polémica política con los judíos y con los húngaros, porque eran las dos únicas fuerzas políticas en su Rumania de juventud. Para argumentar su defensa remite el texto: Un pueblo de solitarios, en el que señala la admiración de Cioran por el pueblo judío. Aunque no es propiamente una apología, sino más bien, esa manera irónica, ambigua y paradojal con la cual trabaja siempre Cioran los temas en toda su obra; sin embargo, sale mejor librado que en sus primeros escritos sobre los judíos. Veámoslo:

10 Cioran E.M. À l'école des Tyrans en (Cioran, 1995: 1005, 1988a: 63). En la traducción española cambia el plural por el singular: Escuela del tirano.
Ser hombre es un drama; ser judío, otro. De este modo, el judío tiene el privilegio de vivir dos veces nuestra condición. Representa la existencia separada por excelencia o, para emplear una expresión con la que los teólogos califican a Dios, lo absolutamente otro [...] Excesivo en todo, emancipado de la tiranía del paisaje, de las ingenuidades del arraigamiento, sin ataduras, acósmico, es el hombre que nunca será de aquí, el hombre venido de otra parte, el extranjero en sí, y que no podría sin equívoco hablar en nombre de los indígenas, de todos [...] Mejor y peor que nosotros, encarna los extremos a los que aspiramos sin alcanzarlos: es nosotros más allá de nosotros mismos... Como su capacidad de absoluto supera a la nuestra, ofrece, para bien y para mal, la imagen ideal de nuestras capacidades. Su soltura para el desequilibrio, la rutina que ha adquirido en él, le convierte en un desquiciado, experto en psiquiatría como en toda clase de terapéuticas, un teórico de sus propios males: no es como nosotros, anormal por accidente o por esnobismo, sino naturalmente, sin esfuerzo y por tradición: tal es la ventaja de un destino genial a la escala de un pueblo [...] ¿Les complació el papel de indeseables? ¿Querían desde el principio estar solos en la Tierra? Lo que es cierto es que aparecieron durante largo tiempo como la encarnación misma del fanatismo y que su inclinación por la idea liberal es, más que innata, adquirida [...] Si los judíos no tuviesen que afrontar más que el antisemitismo profesional, su drama se vería sensiblemente disminuido. Enfrentados de hecho con la casi totalidad de la humanidad, saben que el antisemitismo no representa un fenó- 
meno de época, sino una constante, $\mathrm{y}$ que sus verdugos de ayer empleaban los mismos términos que Tácito... Los habitantes del globo se dividen en dos categorías: los judíos y los no judíos [...] En suma: bien apegados a este mundo, no forman realmente parte de él. Hay algo de no terrestre en su paso por la tierra. ¿Fueron en algún tiempo remoto testigos de un espectáculo de beatitud del que conservan nostalgia? ¿Y que es entonces lo que debieron ver, que escapa a nuestras percepciones? $\mathrm{Su}$ inclinación hacia la utopía no es más que un recuerdo proyectado en el futuro, un vestigio convertido en ideal. Pero es su sino, cuando aspiran al Paraíso, chocan con el Muro de las Lamentaciones (Cioran, 1995: 858, 859, 860, 864, 879; 1988b: 68, 69, 71-72, 77, 103).

Pero Rigoni no hace mención de sus primeros textos, en especial de la década de los años treinta, publicados en el diario rumano Vremea ni a su polémico libro La transfiguración de la Rumania ${ }^{11}$, como da cuenta la cantidad de textos publicados sobre este sombrío tema (nota 11, p. 13). Las siguientes aseveraciones en dicho texto ponen en graves aprietos a Cioran en relación con sus posiciones antisemitas: "La invasión judaica, en las últimas décadas del devenir rumano, ha

11 Este texto es el tercer libro escrito en rumano por Cioran, setenta y tres años después de su primera publicación vuelto a editar-Éditions Humanitas, Bucarest, 1990- En esta edición Cioran suprime el capítulo cuarto y algunos pasajes. Esta obra ha sido fuente de todos los comentarios y polémicas alrededor de su compromiso político con el fascismo rumano de los años 30. Sus planteamientos han marcado una sombra sobre toda su obra. La nueva edición completa -Éditions L'Herne, Paris, 2009- posee un magnífico prefacio de Marta Petreu que da una visión del contexto histórico, político y cultural en que nació dicho texto. hecho del antisemitismo el tema esencial de nuestro nacionalismo (...)". Es comprensible, pero Cioran anota que no se debe exagerar; si Rumania no hubiera contado con ningún judío, no sería por ello menos miserable, ni tendría un nivel histórico más alto, pero por supuesto sí menos corrupción. "Los judíos a lo sumo han retardado la hora solemne de la Rumania, ellos no son en ningún caso la causa de nuestra miseria, de nuestra miseria de siempre".

Un organismo nacional sano se refuerza siempre en la lucha contra los judíos, especialmente cuando ellos invaden un pueblo, cuyos problemas nacionales y sociales no son resueltos por el antisemitismo, que es un acto de purificación y nada más. Los vicios constitutivos de dicho pueblo permanecen los mismos [...] ¿Cuáles son las razones profundas que nos determinan a odiar y a despreciar a los judíos? ¿Por qué no hay un solo hombre sobre la tierra que ame a los judíos ingenuamente, espontáneamente, sin saberlo? ¿De dónde viene el dramatismo de su existencia?

La teoría de las razas parece creada para expresar el sentimiento de separación abisal que distingue un no-judío de un judío. No un abismo cavado por el antisemitismo o por cualquier otra concepción, sino por el antagonismo manifiesto o secreto que caracteriza dos seres de esencias diferentes. El judío no es nuestro semejante, nuestro prójimo, y pensamos disfrutar en la intimidad con él, un abismo nos separa, querámoslo o no. Se diría que los judíos descienden de otra especie de monos que nosotros, han sido condenados $a b$ 
initio a una tragedia estéril, a esperanzas eternamente decepcionadas. No podemos acercarnos a ellos con humanidad pues el judío es primero judío y luego hombre. Fenómeno que se produce tanto en su conciencia como en la nuestra".

[...] Evocar el vampirismo y la agresividad de los judíos significa señalar una de sus características sin atenuar por lo tanto en nada el misterio de la naturaleza judaica [...] Considerado desde una perspectiva de la historia universal, la cuestión judía es absolutamente insoluble ${ }^{12}$.

Finalmente, Rigoni termina compartiendo con Cioran respecto al pueblo judío y su historia que ambos estaban: "fascinados y aterrados por la singularidad absoluta de su destino...".

\section{La muerte de su amigo Cioran}

El capítulo "In memoriam" está dedicado a la muerte de Cioran. Para sus amigos lo habían perdido antes de morir, esa secreta afinidad de la lucidez se había eclipsado para siempre, "deslizándose hacia el silencio y la sombra". Poseía la peor enfermedad: estaba muerto en vida. Al final de su vida repetía: "algo se ha roto". Contrariamente a lo que piensa el común, estos espíritus devastadores, estos pensadores crueles, conservan una expresión muy dulce y una sensibilidad más delicada. Miembro de la comunidad espiritual a la que

12 Estos textos citados pertenecen al capítulo cuarto titulado: "Collectivisme national"-que fuera eliminado por Cioran, como dijimos ya, en la edición de 1990- el tono es el mismo en toda la obra. Su referencia a los judíos se juega en medio de una ironía, de una ambigüedad, de una tensión paradojal que en estudio más amplio se podría tomar partido acerca del antisemitismo militante de Cioran (Cioran, 2009:. 222 y 223). pertenece también Leopardi, no solo tiene una afinidad de su cosmovisión, una desesperanza compartida; sino que son similares en sus experiencias y tormentos más profundos, comenzando por el "ennui". Es la experiencia metafísica del "ennui" la que acerca Cioran a Pascal, incluso confiesa que elaboró el texto contra Valéry por haber denigrado de Pascal. Es por esta misma razón que admira a Baudelaire ${ }^{13}$.

Cioran no era un profesional, ni un erudito, aunque sus preocupaciones eran de orden vital, desenmascara los trucos que ayudan al pensamiento a preservarse de la verdad que los devorará. Tal como se pone de manifiesto en La obsesión de lo esencial:

Sólo prosperan en filosofía los que se detienen a propósito; los que aceptan la limitación y el confort de un estadio razonable de inquietud. Todo problema, si se toca el fondo, lleva a la bancarrota y deja el intelecto al descubierto: no hay ya ni preguntas ni respuestas en un espacio sin horizontes. Las interrogaciones se vuelven contra el espíritu que las concibió: se convierte en víctima suya. Todo le es hostil: su propia soledad, su propia audacia, el absoluto opaco, los dioses inverificables y la nada manifiesta: ¡Malhaya quien, llegado a un cierto momento de lo esencial, no hace alto! La historia muestra que los pensadores que subieron hasta el final por la escala de las preguntas, que pusieron el pie en el último escalón, el del absurdo, no han legado a la posteridad más que

13 Rigoni cuenta la anécdota, que paseando un día por el jardín de Luxemburgo, una rama se ha enrollado en la estatua de Baudelaire. Cioran se moleta por ello. Siendo Rigoni más alto la retira y Cioran exclama: "Salvaste la cabeza de Baudelaire" (Rigoni, 2009: 103). 
un ejemplo de esterilidad, mientras que sus colegas, que se pararon a medio camino, han fecundado el curso del espíritu; han servido a sus semejantes, les han transmitido algún ídolo bien trabajado, algunas supersticiones corteses, algunos errores disfrazados de principios y un sistema de esperanzas. Si hubieran abrazado los peligros de un progreso excesivo, ese desdén de los errores caritativos les hubiera vuelto nocivos para los otros y para sí mismos; hubieran escrito su nombre en los confines del universo y del pensamiento, investigadores malsanos y réprobos áridos, gustadores de vértigos infructuosos, buscadores de sueños que no es lícito soñar... (Cioran, 1995: 652; 1977: 98).

Esto es lo que hace irremplazable a Cioran: su lenguaje que irrita, que socaba en las entrañas del pensamiento para dar cuenta de una manera inaudita otra forma de concebir la reflexión filosófica.

\section{Los recuerdos que deja un amigo}

El último capítulo "Cioran, en mis recuerdos", que le da el título al libro, son una serie de recuerdos que dan cuenta del talante humano y del conocimiento íntimo que poseía Rigoni de Cioran.

El primer recuerdo Rigoni empieza por relatar, cuando comenzó a escribir en el Corriere della Sera. Por aquella época él ignoraba los procedimientos de edición en los diarios. No sabiendo que los títulos corresponden a la redacción, quiso colocarle un titulo a su ensayo filosófico en contra de la divinidad. El título que se le ocurrió fue: Une théologie cynique, pero el anónimo redactor lo cambió por $\mathrm{Dieu}$ existe, mais il est pire que nous. Acerca de este acontecimiento recuerda el día en que con Cioran, citando el título de un artículo que acababa de aparecer en un diario italiano sobre su visión del mundo: "La vida es un vicio". Al respecto Cioran exclama: "Este es un ejemplo de verdadero periodismo". Y, por supuesto, tenía razón. Pero en su caso, el periodista había simplemente tomado uno de sus aforismos, mientras que en mi caso, había transformado la evocación de un concepto teológico de gran alcance en una broma tan casual como despectiva.

El siguiente recuerdo: en 1986 Rigoni pasa una temporada en los Estados Unidos, viaja a New York a visitar a Susan Sontag quien unos años antes había sido presentada por el propio Cioran. Ella había escrito Styles of Radical Will, en la que da una semblanza precoz y pertinente, que borra todo prejuicio. Además, había escrito el prefacio a la edición americana de La tentación de existir. Es por ello, que su obra tenía una cierta difusión en Estados Unidos. En la conversación en un momento determinado Sontag le pregunta a quemarropa a Rigoni, "si Cioran era de derecha”, esta cuestión la inquietaba. Esta situación luego se la comenta a Cioran, quien en un momento de cólera dice: "Dígale que yo era de derecha cuando ella era de Izquierda" (Rigoni, 2009: 110).

El cigarrillo había jugado un papel importante en su vida de escritor. Acostumbraba a decir que se había puesto a escribir aforismos cuando había dejado de fumar, puesto que no tenía la manera de seguir un pensamiento coherente durante un tiempo. Además agregaba sobre el tema: "En mis momentos de abatimiento me digo: tú no eres nadie, pues has sido capaz de dejar de fumar" (Rigoni, 2009: 115).

Cuando Cioran visita a Rigoni en Padua, la primera cosa que quiere ver no son los numerosos monumentos históricos de la ciudad, sino la Basílica de Saint Antoine. Al observar allí los cientos de peregrinos, comenta que 
esta forma de devoción cumple la misma tarea que el psicoanálisis. Luego observan los frescos de Giotto en la chapelle des Scrovegni, se detiene frente a la representación de los Vicios y las Virtudes, y exclama: "los primeros pintan la verdad y los segundos la mentira" (Rigoni, 2009: 117).

Un recuerdo más, en la cubierta del libro de la edición de bolsillo de L'inconvénient d'être né, se encuentra ilustrada una imagen de un pequeño ángel negro, ángel etíope, que Cioran lo había elegido. En la cubierta de los Syllogismes de l'amertume, una pequeña figura análoga que evoca el arte africano: una barca que se posa sobre una media luna amarilla, tomada de un cuadro de Klee. Estas dos figuras es el estilo que prefiere Cioran: entre confesión y provocación, entre lirismo y metafísica.

El último y conmovedor relato narra la última vez que Rigoni su esposa y la compañera de Cioran Simone Boué, visitan a Cioran en el hospital de Broca en la calle Pascal. Cuando entran en la habitación Cioran se despierta de su letargo comatoso. Reconoce a Rigoni esbozando una sonrisa ${ }^{14}$. Y después de una larga visita antes de abandonar la sala, Rigoni toma la mano de Cioran, quien vuelve a abrir los ojos reconociéndolo de nuevo y sonriendo. Es entre esas dos sonrisas espontáneas que Rigoni tiene el último recuerdo: "de un hombre a quien tenía tantas razones de querer como de admirar" (Rigoni, 2009: 120).

\section{Referencias}

Buscioni, P. (2004, marzo-maggio). Emile Cioran. En il Fuoco. Firenze: Polistampa.

14 Ya desde su primer libro había escrito: “(...) pues yo soy el hombre que reirá en el momento supremo, en la agonía final, a la hora de la última tristeza" (Cioran, 1995: 78; 1991:.149).
Castronuovo, A. (2009). Emil Michel Cioran. Napoli: Liguori.

Cioran, E. M. (1988a). Historia y utopía. Barcelona: Tusquets.

Cioran, E. M. (1988b). La tentación de existir. Barcelona: Tusquets.

Cioran, E. M. (1989). Desgarradura. Barcelona: Montesinos.

Cioran, E. M. (1991). En las cimas de la desesperación. Barcelona: Tusquets.

Cioran, E. M. (1992a). Ensayo sobre el pensamiento reaccionario. En Ejercicios de admiración y otros textos. Barcelona: Tusquets.

Cioran, E. M. (1995). Oeuvres. Le précis de décomposition. Gallimard: Paris. Cioran, E. M. (1977). Breviario de podredumbre. Madrid: Taurus.

Cioran, E.M. (1995). Oeuvres. Syllogismes de l'amertume. Gallimard: Paris. Cioran, E. M. (1980). Silogismos de la amargura. Caracas: Monte Ávila.

Cioran E. M. (1995). Oeuvres. Histoire et utopie. Paris: Gallimard.

Cioran, E. M. (1995). Oeuvres. La tentation d'existir. Paris: Gallimard.

Cioran, E.M. (1995). Oeuvres. Ecartelèment. Paris: Gallimard.

Cioran, E. M. (1995). Oeuvres. Sur les cimes $d u$ désespoir. Paris: Gallimard.

Cioran, E.M. (1995). Oeuvres. Joseph de Maistre. Essai sur la pensé réactionaire en Exercises d'admiration. Paris: Gallimard.

Cioran, E.M. (1996). Anthologie du portrait littéraire de Saint Simon à Tocqueville. Paris: Gallimard. 
Cioran, E. M. (1997). Cahiers 1957-1972. Paris: Gallimard.

Cioran, E. M. (2005). Exercises négatifs. En marge du Prècis de décomposition. «Les inédits de Doucet». Paris: Gallimard.

Cioran, E.M. (2009). Transfiguración de la Roumanie. Paris: L'Herne.

Emanuela, C. (2005). Nae Ionescu, Mircea Eliade, Emil Cioran: antiliberalismo nazionalista alla periferia d'Europa. Perugia: Morlacchi.

Jaudeau, S. (1993). Conversazioni con Cioran; seguite da Mistica e saggezza, traduzione di Leopoldo Carra. Parma: Guanda.

Laignel-Lavastine, A. (2008). Il fascismo rimosso: Cioran, Eliade, Ionesco: tre intellettuali rumeni nella bufera del secolo. Traduzione di Laura Verrani. Torino: Utet Librería.

Rigoni, M. A. (2009). Cioran dans mes souvenirs. Paris: P. U. F.

Rizzacasa, A. (2007). Sentinella del nulla. Itinerari meditativi di E. M. Cioran. Perugia: Morlacchi.
Rodda, F. (2006). Cioran, l'antiprofeta: fisionomia di un fallimento. Milano: Mimesis.

Rotiroti, G. (2005). Il demone della lucidità: il caso Cioran tra psicanalisi e filosofía. Soveria Mannelli: Rubbettino.

Savater, F. (1998). Cioran. Un angelo sterminatore. Milano: Frassinelli.

Scapolo, B. (2009). Esercizi di de-fascinazione: saggio su E. M. Cioran. Milano: Mimesis.

Thoma, F. (2010). Per nulla al mondo. Un amore di Cioran. Falconara Marittima: L'orecchio di Van Gogh.

Tripodi, A. (1987). Cioran, metafisico dell'impossibile. L'Aquila: Japadre.

Vizioli, R. L. (2002). La depressione creativa di E. Cioran: quasi un dizionario. Roma: EUR. 